\title{
ENTRE AGOSTINO CARRACCI Y VERONESE: APUNTES SOBRE EL APRENDIZAJE ITALIANO DE FRANCISCO DE HERRERA «EL MOZO» ${ }^{1}$
}

\author{
POR \\ JORGE FERNÁNDEZ-SANTOS ORTIZ-IRIBAS
}

La presencia de Francisco de Herrera «el Mozo» (1627-1685) en Roma se apoyaba, hasta ahora, sobre la sola base del relato de Palomino y por el propio estilo del pintor. La atribución de diez orlas ornamentales (ocho de ellas inéditas) a este artista nos permite establecer su estancia romana en torno a 1649, a la vez que testimonian sobre una faceta - el grabado calcográfico - hasta ahora desconocida de la actividad de Herrera. También dan fe de la evolución del propio Herrera desde una casi total mímesis del estilo paterno hasta unas maneras ya claramente personales, influidas por el medio romano. De la Roma de mediados del siglo XVII debió de datar también el peculiar neo-venecianismo de Herrera que, por su riqueza de matices, lo singulariza con respecto a sus contemporáneos españoles.

Palabras clave: Pintura española s. XvII; Herrera «el Mozo»; Herrera «el Viejo».

The presence in Rome of Francisco de Herrera «the Younger» (1627-1685) was based until now solely on Palomino's biographical account and on stylistic evidence. Ten engraved decorative cartouches attributed to the artist (only two of which were already known), establish Herrera's sojourn in Rome to around 1649. They also shed light on his activities as an engraver, a previously unknown facet of his artistic production. Likewise, they attest to Herrera's stylistic evolution from virtual imitation of his father's (Herrera «the Elder») manner to one that becomes clearly personal under the influence of the Roman milieu. Mid-seventeenth century Rome may be also responsible for Herrera's nuanced and complex neo-Venetianism, a trait that sets him apart from his contemporaries in Spain.

Key words: Spanish painting; seventeenth-century; Herrera «the Younger»; Herrera «the Elder».

Con la excepción del reticente Kinkead ${ }^{2}$, la crítica ha sido unánime en apoyar la hipótesis de un viaje a Italia de Herrera «el Mozo» ${ }^{3}$ basándose sólo en el relato de Palomino ${ }^{4}$. La falta de

\footnotetext{
${ }^{1}$ Este artículo no habría sido posible sin la generosa disponibilidad de Monseñor José Luis González Novalín y del Padre Francisco Delgado (Iglesia Nacional Española de Santiago y Montserrat en Roma), quienes merecen todo mi agradecimiento. Las sugerencias de Anna Reuter me han sido de gran utilidad. Agradezco asimismo la hospitalidad de la Real Academia de España en Roma, en las personas de su director Juan Carlos Elorza y secretario Enrique de Álvaro. Doy las gracias también a Manuela Mena y a Almudena Pérez de Tudela por haber leído el artículo.

2 Duncan Kinkead, «Francisco de Herrera y Aguilar», in The Dictionary of Art, ed. J. Turner, Londres / Nueva York 1996, vol. 14, pp. 470-472.

${ }^{3}$ Alfonso E. Pérez Sánchez, Carreño, Rizi, Herrera y la pintura madrileña de su tiempo (1650-1700), Madrid 1986, pp. 91-101 (pp. 92-94). Jonathan Brown, «Pen drawings by Herrera the Younger», en Hortus Imaginum: Essays in Western Art, edd. R. Enggass y M. Stokstad, Lawrence (Kansas) 1974, pp. 129-138 (p. 129).

${ }^{4}$ Antonio A. Palomino de Castro y Velasco, Vidas, ed. N. Ayalla Mallory, Madrid 1986, p. 281.
} 
constatación documental no ha sido obstáculo para que, especialmente después de que María Luisa Caturla documentase la ejecución del Triunfo de San Hermenegildo (Museo del Prado) en $1654^{5}$, se viera este singular lienzo como un fruto temprano del aprendizaje romano de Francisco de Herrera e Hinestrosa (1627-1685). Lo cierto es que esta obra, realizada para el retablo mayor de los Carmelitas Descalzos de Madrid, contrasta fuertemente con el único lienzo que, según Valdivieso, podemos fechar con anterioridad a la etapa romana de Herrera ${ }^{6}$. En concreto, Pérez Sánchez propuso una horquilla temporal para la estancia italiana de Herrera (1647$1650)^{7}$ cuya validez viene avalada por el hallazgo de una serie de grabados de su mano en un fondo documental romano. Contrarrestando la falta de testimonios directos del paso por Italia del pintor sevillano, esta serie nos permite fechar en torno a 1649 su presencia en la Ciudad Eterna.

Lo conocido con certeza de la actividad como grabador de Francisco de Herrera «el Mozo» se circunscribe, en gran medida, a su aportación al libro que Torre Farfán dedica a las fiestas hispalenses en ocasión de la canonización de Fernando III de Castilla — una aportación que parece no fue más allá del dibujo de algunas composiciones, dejando la labor de incisión en manos de Matías de Arteaga ${ }^{8}$. Elizabeth Du Gué Trapier publicó por primera vez un marco ornamental grabado, firmado por «F. de Herrera» y fechado en 1649, que no dudó en atribuir a Herrera «el Mozo» ${ }^{9}$. Esta atribución, sin embargo, fue rechazada en favor de su progenitor por la crítica posterior que alegaba la falta de ejemplos de esta actividad en el joven Herrera ${ }^{10}$. Un segundo marco ornamental, esta vez sin firmar, pero de obvia afinidad formal con el anterior, fue atribuido a Herrera «el Viejo» siguiendo idéntico razonamiento ${ }^{11}$. Se indicó que ambos marcos ornamentales probablemente formasen parte de una serie, siendo concebidos como orlas decorativas de uso múltiple ${ }^{12}$. La zona central vacía, ciertamente, se prestaba a varios usos, desde el enmarque de un dibujo al realce de un título de obra manuscrita. El hallazgo de otros ochos marcos, uno de ellos firmado por «Francisco de Herrera», respalda la hipótesis de que se tratase de una serie, aunque nos lleva también a retomar la atribución inicial a Herrera «el Mozo» de Du Gué Trapier.

Los ochos nuevos marcos, además de los dos ya conocidos, fueron utilizados como frontispicios para una serie de códices manuscritos del siglo XVIII, pertenecientes a la biblioteca aneja al Archivo de la Embajada de España ante la Santa Sede, hoy depositada en la Iglesia Nacional Española de Santiago y Montserrat en Roma. En concreto, todos los grabados firmados o atribuibles a Francisco de Herrera que hemos encontrado en este fondo corresponden a obras pertenecientes a José García del Pino, notario y archivero de la Embajada ${ }^{13}$, adquiridas en 1780 por

\footnotetext{
${ }^{5}$ María Luisa Caturla, «La verdadera fecha del retablo madrileño de San Hermenegildo», en Actas del XXIII Congreso Internacional de Historia del Arte: España entre el Mediterráneo y el Atlántico, Granada 1976-1978, vol. 3, pp. 49-55.

${ }^{6}$ Santa Catalina de Siena ante el Papa Urbano VI (véase Pérez Sánchez 1986, p. 266, cat. no. 99).

${ }^{7}$ Pérez Sánchez 1986, p. 92.

${ }^{8}$ Antonio de la Banda y Vargas, «Matías de Arteaga, grabador», Boletín de Bellas Artes, 6 (1978), pp. 73-131 (p. 77); Antonio Martínez Ripoll, «Francisco de Herrera 'El Viejo', grabador», en Actas del XXIII Congreso Internacional de Historia del Arte: España entre el Mediterráneo y el Atlántico, Granada 1976-1978, vol. 3, pp. 145-154 (p. 154, nota 20); Antonio Gallego Gallego, Historia del grabado en España, Madrid 1999, p. 215.

${ }^{9}$ Elizabeth Du Gué Trapier, Valdés Leal: Spanish Baroque Painter, Nueva York 1960, p. 43 y fig. 103.

${ }^{10}$ Antonio Martínez Ripoll, «Francisco de Herrera 'El Viejo', grabador», en Actas del XXIII Congreso Internacional de Historia del Arte: España entre el Mediterráneo y el Atlántico, Granada 1976-1978, vol. 3, pp. 145-154 (p. 154, nota 20); Antonio Gallego Gallego, Madrid 1999, p. 215. Como notara Pérez Sánchez 1986, p. 94, Herrera «el Mozo» menciona en su testamento «estampas y dibujos que hubiere de mi mano». Aunque la crítica parece haberse inclinado por interpretar estas estampas como aguafuertes hechos a partir de dibujos de Herrera, la referencia es lo suficientemente ambigua para dejar abierta la posibilidad de que Herrera dejara incisiones de su propia mano. Véase José López Navío, «Testamento de Francisco de Herrera, El Joven», Archivo Hispalense, 35.110 (1961), pp. 261-274.

${ }^{11}$ Antonio Martínez Ripoll, Francisco de Herrera «el Viejo», Sevilla 1978, p. 248, cat. nos. G.5 y G.6.

12 Ibid.

${ }^{13}$ Los codd. 309, 310 y 312 van firmados con las iniciales J. G. D. P. Los codd. 90, 204, 223, 224 y 256, aunque anónimos, son también autógrafos de José García del Pino (cfr. José M. Pou y Martí, Archivo de la Embajada de España cer-
}

AEA, LXXVIII, 2005, 311, pp. 245 a 261 
el embajador duque de Grimaldi ${ }^{14}$. El valor documental de estas, en su mayoría, copias dieciochescas de documentos se acrecentó sobremanera con el fatídico incendio de 15 de enero de $1738{ }^{15}$, que dio al traste con gran parte del archivo del Palazzo di Spagna. Conviene, sin embargo, dejar claro que la labor de compilación emprendida por José García del Pino precede al incendio y no parece tampoco interrumpirse tras éste ${ }^{16}$. Muerto el 16 de diciembre 1762 sin que se pudiese llegar a un acuerdo con la Embajada para la adquisición de sus códices, ésta hubo de esperar hasta 1780 en que se adquieren de Maria Carducci, viuda de su hijo Joaquín García del Pino, fallecido en ese mismo año. Enmarcados dentro de un amplísimo, aunque por fuerza asistemático ${ }^{17}$, esfuerzo de recopilación y trascripción de documentos, resulta difícil datar con precisión los distintos códices García del Pino, pudiendo éstos haberse realizado en fechas tempranas del siglo XvIII o, incluso, poco antes de su muerte. Parece lógico, sin embargo, pensar que el contingente más sustancioso de éstos debió de finalizarse antes del devastador incendio, en estrecho contacto con fondos documentales de la Embajada aún intactos. De hecho, para la mitad de los diez códices que aquí nos ocupan, podemos establecer un término ante quem entre 1738 y 1740 . No es nada improbable que muchos otros se sitúen en torno a 1716-1718 o incluso antes ${ }^{18}$.

No se pretende catalogar los distintos tipos de grabados que, a guisa de frontispicios, encabezan un gran número de los códices de la Embajada. Resulta claro que se trata, con la notable excepción de la serie de Francisco de Herrera, de grabado predominantemente romano - aunque de artistas de procedencias varias - sin que se encuentren grabados o dibujos que, en principio, puedan atribuirse a una mano española. Destaca por la admirable fluidez de su dibujo y por su calidad compositiva, uno del cortonesco Ciro Ferri, grabado por Jean Couvay (1622-ca. 1680) ${ }^{19}$. Los del genovés Bernardo Castelli (1557-1629) son bien reconocibles (aun cuando no vayan firmados) por el uso de un sombreado intenso y por su énfasis escultórico y

ca de la Santa Sede: índice analítico de los códices de la Biblioteca contigua al Archivo, Roma 1925, pp. vi-vii). El cod. 128 es sólo parcialmente autógrafo, hallándose en él otras manos colaboradoras. Por último, el cod. 257 es un ms. del siglo XVI probablemente reencuadernado por García del Pino.

${ }^{14}$ Para datos tocantes al Archivo de la Embajada Española ante la Santa Sede resulta de consulta obligada la introducción de: Pou y Martí 1925, pp. III-Ix. Véase, del mismo autor, el proemio a: Archivo de la Embajada de España cerca de la Santa Sede, Roma 1915-1935, vol. 1, pp. vii-xxxii.

${ }^{15}$ BAEESS, cod. 1, fol. 20. Alessandra Anselmi, Il Palazzo dell'Ambasciata di Spagna presso la Santa Sede, Roma 2001, pp. 112 y 117 (nota 74).

${ }^{16}$ En concreto, el archivero Aniello Nipho lo llama en agosto de 1738 para que se haga cargo del «escrutinio» de los documentos tras el incendio (BAEESS, cod. 2, fol. $2^{\mathrm{r}}$ ). Por desgracia, a la muerte de Nipho, acaecida el 25 de marzo de 1739 (ibid., cod. $1,12^{r}$ ), y a pesar de ser la única persona competente y poseedora de los índices del archivo (ibid., cod. 2 , fols. 193r-218 ), se prescinde de los servicios de García del Pino. A la incuria del archivero sucesor de Nipho, el abate Bernardo Bucci, un protegido del cardenal Troiano Acquaviva y del marqués Scotti (ibid., fol. $94^{v}$ ), se unió el interés del propio Acquaviva por minimizar cara a Madrid la entidad del incendio, que destruyó o dañó la práctica totalidad del archivo (ibid. fols. $89^{\mathrm{r}}-113^{\mathrm{v}}$; cod. 1 , fols. $21^{\mathrm{v}}-23^{\mathrm{v}}$ ).

${ }_{17}$ José García del Pino, a pesar de su probada competencia archivística (cfr. BAEESS, cod. 2, fols. 29r $-59^{\mathrm{r}}, 115^{\mathrm{r}}-140^{\mathrm{r}}$ y cod. 3, passim), no contó con el menor respaldo del Cardenal Troiano Acquaviva.

${ }^{18}$ Téngase en cuenta que la vinculación de José García del Pino tanto con la Embajada como con la Nación española en Roma era estrecha y arraigada familiarmente. Su abuelo, el gallego Juan García del Pino, fue el primer maestro de ceremonias de la Embajada, con título expedido el 15 de junio de 1657 (BAEESS, cod. 66, fol. 142) mientras que su padre, también llamado Juan y originario de Córdoba, ejerce oficialmente las funciones de notario diputado del Real Palacio de España y secretario de la Nación Española en Roma desde 1 de junio de 1683 (BAEESS, cod. 50, fol. 176; AGMAE: AEESS, leg. 90, fol. 382v), cubriendo la vacante dejada por Jacques-Antoine Redoutey, que marchó a Nápoles en el séquito de Gaspar de Haro y Guzmán, VII marqués del Carpio. Juan García del Pino continúa en este puesto hasta 1699, año en que le sucede su hijo José (BAEESS, cod. 1, fols. 32r-33r). Aunque ya ejercía funciones análogas antes de 1715, el 24 de febrero de 1716 (ibid., fol. 11 ${ }^{v}$ ) José García del Pino recibe título de archivero del Real Palacio de S. M. en Roma (ibid., cod. 50 , fol. 218), siendo el quinto en ocupar este puesto desde su creación en 1657 —puesto que pierde dos años después al ser reintegrado en el cargo Aniello Nipho 212).

19 Utilizado como frontispicio del cod. 214. De éste existe además una réplica invertida, notablemente más tosca (cod. 
precisión de dibujo, claramente deudor de fórmulas manieristas ${ }^{20}$. Destaca asimismo la reutilización extensiva de una plancha de Giovanni Luigi Valesio (1583?-1633) que, a pesar de no ir firmada, resulta inconfundible. Importa señalar que tanto Valesio como Castelli estuvieron en Roma y que, además, la plancha de Valesio es de segura factura romana ${ }^{21}$. Todo esto vendría a corroborar que José García del Pino echó mano de un fondo de grabados existente en Roma ${ }^{22}$. Aunque algunas series documentales, como la dedicada a bulas y breves, se extiendan a varios volúmenes, no parece haber habido ningún tipo de criterio uniforme en el uso de estas orlas grabadas - lo cual también encajaría con una reutilización ad hoc de un fondo de grabado preexistente y no con una tirada controlada a partir de unas planchas a disposición de José García del Pino. Se trataba, además, de un material heteróclito del siglo xvII, posiblemente un remanente de bottega o imprenta adquirido en la misma Roma o, quizás, de un lote de grabados adquiridos con anterioridad por la Embajada Española o por la Confraternidad de San Giacomo degli Spagnoli, a las que García del Pino estuvo asociado en calidad de notario diputado. Es obvio, además, que al tratarse de grabados de fecha considerablemente anterior, un encargo de José García del Pino queda taxativamente excluido. Tampoco parece probable que estuviesen asociados a un encargo previo del siglo xviI, ya fuera por parte de San Giacomo degli Spagnoli o de la Embajada Española, ya que nada en las orlas las singulariza para uso de una institución o personaje específico. Por el contrario, se trata de grabados sueltos, de manos y fechas distintas ${ }^{23}$, sobre el común denominador de haber sido utilizados como orla o marco ornamental de los títulos de los distintos códices García del Pino, aprovechando su carácter decididamente neutro, apto para usos variados. Aunque se pudiera decir que los ángeles «reggistemma» de Ciro Ferri son más acordes para un uso eclesiástico que algún mascarón de la serie herreriana, estas sutilezas no parecen haber condicionado el uso indiscriminado que de ellos hace García del Pino, que usa dos o más ejemplares de un mismo grabado para encabezar códices del todo inconexos mientras que no duda en realzar los tomos de una misma serie documental con orlas diversas.

Dada las notables carencias españolas en grabado resultaría incluso paradójico que uno de los escasos artistas de relieve en este campo, el sevillano Herrera «el Viejo» ${ }^{24}$, se hubiese dedicado con tanto ahínco a lo que es sin duda un registro comparativamente modesto y del todo infrecuente en nuestro país. De hecho, el último grabado a buril fechado y firmado que conocemos fehacientemente de él data de $1627^{25}$, veintidós años antes de la serie que aquí estudiamos, es una ambiciosa y abigarrada composición presidida por la Trinidad con figuras orantes de los reyes y de los condes-duques de Olivares ${ }^{26}$. A falta de otros datos, una serie de cartelas decorativas como la que nos ocupa parece más acorde con la producción de un artista joven,

\footnotetext{
${ }^{20}$ Véase, por ejemplo, codd. 236 y 152 . El del cod. 84, de factura más sencilla, va firmado.

${ }^{21}$ Reproducida en The Illustrated Bartsch, 40/1 (olim 18/2), p. 76. Valesio se traslada a Roma al servicio de los Ludovisi ca. 1620-1622. Giacomo Lodi utiliza la plancha de Valesio, que fue grabada para ser incluida en su relación de las exequias de Gregorio XV celebradas en la catedral de Bolonia (ibid., vol 41 (olim 19/1), p. 353).

${ }^{22}$ Como bien subraya Michael Bury, The Print in Italy 1550-1620, Londres 2001, pp. 126-127, el carácter local de mucho de lo que producía Roma en grabado no ha sido tenido en cuenta por darse la circunstancia que lo romano tenía con frecuencia importancia universal.

${ }^{23}$ Ya desde finales del siglo XVI se perfila en Roma la figura del artista grabador independiente, no siempre de origen romano, que lleva a cabo encargos específicos (Bury 2001, p. 125).

${ }^{24}$ Gallego Gallego 1999, p. 213; Antonio Moreno Garrido y Miguel Ángel Gamonal, «Contribución al estudio del grabado sevillano en la época de Murillo», Goya, 181-182 (1984), pp. 30-36 (p. 31).

${ }^{25}$ Sabemos que en 1633 el Ayuntamiento de Sevilla pagó 200 reales a Herrera «el Viejo» por la iluminación de una estampa de San Fernando, probablemente abierta por él mismo y hoy desconocida (Gallego Gallego 1999, p. 212).

${ }^{26}$ Aunque lo define justamente como su obra más destacada en este género, Martínez Ripoll 1976-1978, p. 148, no deja de señalar su carácter arcaizante. Además de la copia en la BNM (Invent. 14547) se debe añadir la encontrada en el Colegio de Arquitectos de Valencia (sig. R 103) por Alfonso E. Pérez Sánchez y Benito Navarrete Prieto, «Sobre Herrera 'El Viejo'», Archivo Español de Arte, 69.276 (1996), pp. 365-387 (p. 366).
}

$A E A$, LXXVIII, 2005, 311, pp. 245 a 261 
sujeto a una jerarquía de taller o, en caso de actuar por cuenta propia, supeditado a encargos de segundo orden. Por otro lado, la evidente calidad y la afinidad formal de dos cartelas, de las que se conservan sendos ejemplares, aún sin utilizar, en el Metropolitan Museum de Nueva York (figs. 2 y 8), con tarjas y cartelas de Herrera «el Viejo», aparte de la maestría en el manejo del buril y una firmeza de trazo bien característica, llevaron a Antonio Martínez Ripoll a atribuirlas a Herrera «el Viejo» ${ }^{27}$. Ciertamente, los argumentos de índole formal invocados eran, a falta de ejemplos de talla dulce de Herrera «el Joven», difíciles de soslayar. Sin embargo, la existencia en un fondo documental como el anteriormente descrito de la que ya sin duda podemos calificar como una serie de grabados, nos induce a replantear la atribución desde los escasos datos que, gracias a Palomino ${ }^{28}$, conocemos de la biografía y actividad del joven Herrera. Al disponer de un muestrario notablemente enriquecido, pasando de dos a diez cartelas, podemos asimismo plantearnos rasgos estilísticos y compositivos que, por su excepcionalidad, no encuentran fácil acomodo en la producción de Herrera «el Viejo», poco dado a innovaciones en materia pictórica y relativamente reacio a la experimentación en su producción gráfica ${ }^{29}$.

Recuérdese que la única cartela fechada de la serie data de 1649 (fig. 2). Esta fecha, junto con el carácter homogéneo de la serie y su procedencia romana, parece indicar como altamente probable la ejecución de esta serie de grabados en Roma, durante la estancia de Herrera «el Mozo» en aquella ciudad. A menos que se sostenga la importación desde España de un género de grabado en el que las imprentas romanas estarían considerablemente mejor surtidas que las españolas $^{30}$, la propia serie ofrece indicios que concuerdan con un medio romano. Las filigranas observables en seis de las diez cartelas aquí reproducidas (incluida una de las firmadas por Herrera) aportan además un ulterior elemento probatorio, al evidenciar el uso de papel del centro de Italia, rubricando de modo evidente la localización de las cartelas en una serie documental romana surgida en la primera mitad del siglo XvIII ${ }^{31}$. Importa además notar que, dentro de la propia serie, se puede observar un cierto replanteamiento desde un estilo fuertemente mediatizado por el de Herrera «el Viejo» (fig. 1) a variaciones arriesgadas e imaginativas en las

\footnotetext{
${ }^{27}$ Martínez Ripoll 1978, p. 248.

${ }^{28}$ Palomino de Castro 1986, pp. 280-284.

${ }^{29}$ Esta apreciación vendría matizada en parte por lo que respecta al dibujo; véase, Pérez Sánchez y Navarrete Prieto 1996, pp. 365-387. Por lo que respecta al grabado, las líneas maestras de Herrera «el Viejo» no parecen haber evolucionado significativamente; cfr. Martínez Ripoll 1978, figs. $104-107$ y pp. 246-248.

${ }^{30}$ Bury 2001, p. 126, deja claro que la publicación en Roma de planchas hechas fuera de Roma era del todo excepcional. En 1735 la imprenta De Rossi tenía a la venta «targhe» y «cartelle» ornamentales de Agostino Mitelli: «Targhe, e Cartelle, con varj ornamenti, invenzione, e intaglio in acqua forte di Agostino Mitelli, libro in 13. quarti fogli imperiali bajocchi 40 / Targhe, e Cartelle diverse, con varii ornamenti, invenzioni, e intagli in acqua forte del medesimo Agostino Mitelli, libro in 20. quarti fogli imperiali ba. 60 / Altre invenzioni di Cartelle, con diversi ornamenti, invenzione, e intaglio in acqua forte del sudetto Agostino Mitelli, libro in 13. quarti fogli reali. ba. 20», A. Grelle Iusco, Indice delle stampe Intagliate in Rame a bulino $e$ in acqua forte Esistenti nella Stamparia di Lorenzo Filippo de' Rossi Appresso Santa Maria della Pace in Roma, MDCCXXXV. Contributo alla storia di una Stamperia romana, Roma 1996, pp. 320-322 [pp. 90-91].

${ }^{31}$ Un origen sevillano de estos grabados exigiría la costosa importación a Roma de las planchas o, por el contrario, la inusitada utilización de papel romano en la Sevilla de la época, seguida de una no menos inusitada exportación de estampas sevillanas a Roma - casos ambos no sólo inverosímiles sino en contradicción evidente con la factura decididamente romana del fondo documental reunido por José García del Pino. En los frontispicios grabados de los codd. 90, 224, 256, 257 y 310 se evidencia una filigrana consistente en una estrella de seis puntas inscrita en un círculo y coronada por una cruz. Esta filigrana es de clarísimo origen italiano y viene relacionada con la zona central de la península italiana en los siglos XVI y XVII (Rossana Lanfiuti Baldi, 'Filigrane', en La Collezione del Principe: da Leonardo a Goya, ed. por E. Antetomaso y G. Mariani, Roma 2004, pp. 393-441 (p. 419, no. 12 y p. 430, no. 54); Giulia Fusconi, Disegni decorativi del barocco romano, Roma 1986, pp. 169-175, nos. 58, 82, 109, 116; Charles-Moïse Briquet, Les Filigranes: Dictionnaire Historique des Marques du Papier, Hildsheim / Nueva York 1977, vol. II, p. 353, no. 6089). En el frontispicio del cod. 223 se detecta una filigrana consistente en una paloma sobre tres montes e inscrita en un círculo, también originaria de la zona central de Italia en los siglos XVII-XVIII (E. Heawood, Historical Review of Watermarks, Amsterdam 1950, n. 124; Lanfiuti Baldi 2004, p. 427, no. 40 y p. 433, no. 61; Fusconi 1986, pp. 169-175, nos. 85, 92, 106, 110, 122 y 134).
} 

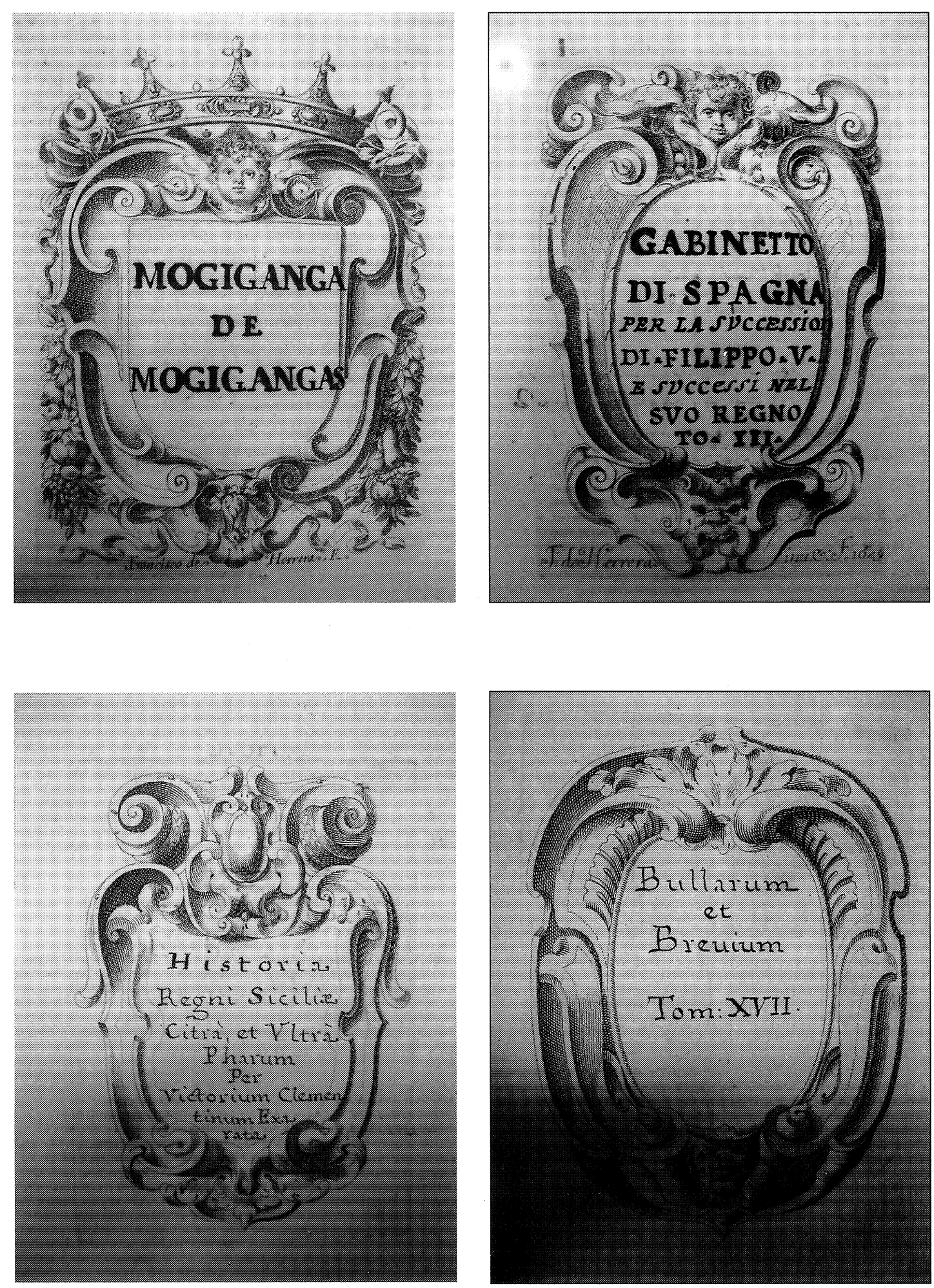

Fig. 1. Grabado de Francisco de Herrera y caligrafía de José García del Pino. Frontispicio del códice 81 (BAEESS, Roma). Fig. 2. Grabado de Francisco de Herrera y caligrafía de José García del Pino. Frontispicio del códice 128 (BAEESS, Roma). Fig. 3. Grabado de Francisco de Herrera y caligrafía de José García del Pino. Frontispicio del códice 204 (BAEESS, Roma). Fig. 4. Grabado de Francisco de Herrera y caligrafía de José García del Pino. Frontispicio del códice 223 (BAEESS, Roma).

$A E A$, LXXVIII, 2005, 311, pp. 245 a 261 
que se traslucen unos bríos e, incluso, un cierto sesgo humorístico (fig. 8 ) $^{32}$ bien lejano de la sequedad solemne de este maestro.

No cabe duda que el modus operandi técnico observable en algunas de estas orlas no difiere considerablemente de lo conocido de Herrera «el Viejo» (la ya mencionada fig. 1), caracterizado por el uso ortodoxo del entrecruzado para sombrear, por los juegos de curvas superpuestas $\mathrm{y}$, en ocasiones, por la presencia de delicadas líneas discontinuas. La precisión del dibujo se une a un uso estratégico del sombreado, consiguiéndose de modo muy económico unos notables efectos de modelado. Predominan elementos como los roleos, las espirales o cintas anudadas de las que penden frutos ${ }^{33}$. Es, claramente, el repertorio que se hace evidente en la primera cartela (fig. 1). Las nueve cartelas restantes, de proporciones más esbeltas y llenando más sabiamente la zona de impresión, evidencian, sin embargo, un repertorio menos convencional. La disparidad entre la primera cartela y las restantes nueve apunta a un abandono por parte de Herrera «el Mozo» de fórmulas compositivas aprendidas en beneficio de soluciones más arriesgadas. No resultaría esto del todo lejano de un Herrera que, emancipado de la disciplina paterna, portase consigo a Roma el bagaje de un oficio bien aprendido ${ }^{34} \mathrm{y}$ las inquietudes propias de un joven de gran talento y curiosidad. Dada su posición subalterna, no sorprendería que «el Mozo» hubiese asimilado en el taller paterno, aparte del oficio de la pintura, el grabado en dulce y una cierta manera áspera de afrontar el dibujo a tinta ${ }^{35}$. Este tipo de ocupación vendría casi impuesto por una tradición familiar arraigada ${ }^{36}$. Parte de la maduración de Herrera como artista excepcional consistiría precisamente en la superación de esquemas heredados, algo para lo que la experiencia italiana sería decisiva.

La segunda cartela (fig. 2) sorprende por la calidad de su dibujo, con un admirable putto borrominesco y una magnífica máscara grotesca en tensa yuxtaposición. Ambas se enlazan por una elegante curva compuesta que enmarca magistralmente el óvalo central. Se trata de una solución depurada, de una factura a la vez simple y rica en matices que demuestra una finura compositiva muy superior a la primera (fig. 1). Se trata, compositivamente, de la mejor de la serie, haciendo gala de una gran maestría en la representación de las curvas en el espacio y un aguzado sentido de los efectos lumínicos. Frente al entrecruzamiento apelmazado y algo monótono de la cartela primera (fig. 1), Herrera selecciona, con gran criterio, unas pocas zonas en que las mallas de buriladas se densifican hasta el negro casi sólido con el objeto de acrecentar el efecto escultórico. De hecho, si algo caracteriza a esta serie de orlas es un uso más plástico del sombreado en función de una versátil exploración tridimensional del ornato, algo lejos de la impostación más convencional de las tarjas de Herrera «el Viejo», tanto en grabado

\footnotetext{
${ }^{32}$ Cfr. Pérez Sánchez y Navarrete Prieto 1995, pp. 170-171, cat. no. 68, que recoge un dibujo de un santo en pluma gruesa y tinta sepia (BNM Barcia 385) con una inscripción autógrafa de Herrera «el Mozo» («s ${ }^{\mathrm{n}}$ quien V.m. quisiere») que, al decir de los autores del catálogo, «muestra también un mucho de humor y desenfado, que encaja sin dificultad con lo que conocemos del joven Herrera».

${ }^{33}$ Estas características se evidencian particularmente en el Patronato de la Orden Trinitaria; véase Martínez Ripoll 1978, figs. 104-107 (especialmente fig. 107).

${ }^{34}$ Ya pasados los veinte años, Herrera debía hallarse ya «muy adelantado» en el momento de su viaje a Italia, como afirma Palomino de Castro 1986, p. 281.

${ }^{35}$ Sobre la permanencia de la escuela paterna en Herrera «el Mozo», véase Jonathan Brown, «Drawings by Herrera the Younger and a Follower», Master Drawings, 13 (1975), pp. 235-240 (p. 238, no. 4), con referencia a BNM Barcia 373; Brown 1974, figs. 93-94; Pérez Sánchez y Navarrete Prieto 1995, pp. 172-173, cat. no. 69, comentan el uso de la pluma gruesa de caña por parte de Herrera «el Mozo» como algo «heredado desde luego de su padre». Enrique Lafuente Ferrari, Breve historia de la pintura española, Madrid 1953, p. 367, vio en la pintura del joven Herrera, al lado de la teatralidad italiana, «el mismo arte de brutal fogosidad de su padre y aun los mismos tipos de ancianos gesticulantes y despeinados».

${ }^{36}$ Aparte de la actividad de grabador de Herrera «el Viejo», el propio medio familiar propiciaba este tipo de actividad. Juan de Herrera, hermano del anterior, era iluminador de libros y se sabe que al menos realizó el diseño de una portada sacada a buril por Alardo de Pompa en 1632. El padre de ambos, Juan de Herrera y Aguilar, tenía a su vez un taller dedicado a la producción libreril. Véase Teresa Laguna Paúl, «Juan de Herrera y las reglas de la cofradía de la Vera-Cruz. Una contribución al estudio de la miniatura sevillana del siglo xvil», Laboratorio de arte, 8 (1995), pp. 127-156.
} 
como en estuco ${ }^{37}$. La tercera (fig. 3) presenta un dinamismo en los resaltes y recovecos que, a pesar de su complejidad, no degeneran en lo anecdótico; la variedad en las tallas abiertas, tanto lineales como en tramas romboidales, parece recrearse en la sinuosidad de las superficies dentro de una acentuación modulada del claroscuro. La quinta (fig. 5) refleja idénticas estrategias, pero lastrada por una composición menos lograda, en la que apenas se aprecia contraste entre zonas más o menos densas. Tampoco la cuarta (fig. 4) resulta especialmente lograda, quizás debido a la concentración de sombras en el mascarón inferior, falto de un contrapeso suficiente en la parte superior. La novena (fig. 9) y, en menor medida, la sexta (fig. 6) quizás adolezcan de cierta saturación. En ambos casos las carátulas femeninas jerarquizan la composición que, en el caso de la novena cartela (fig. 9), se complementa con un bucráneo enmarcado por festones de frutas en la zona inferior. La sexta tarja (fig. 6) opta por una mayor claridad compositiva, destacando asimismo por la versatilidad del sombreado. Frente al mascarón inferior de la cuarta (fig. 4), aprisionado entre dos roleos, la séptima (fig. 7) plantea una continuidad entre máscara y curvas que preludia el ingenioso mascarón de reminiscencias carraccescas que preside la orla octava (fig. 8) ${ }^{38}$. Muy posiblemente, la coherente sobriedad de la última (fig. 10) se vea perjudicada por un coronamiento vegetal algo anodino. Aunque, en mi opinión, la segunda, tercera, sexta y octava sean compositivamente más satisfactorias, todas ellas comparten un gran dominio técnico supeditado a una fértil invención, capaz de transformar un cometido modesto en un desafío creativo - algo, por otro lado, de difícil parangón en el grabado español de 1649.

Desde un análisis más específico, un rasgo llamativo de la serie que aquí adscribimos al joven Herrera es el sutil efecto de vibración que se consigue en los recovecos en sombra ${ }^{39}$. El cruce en oblicuo de buriladas curvas, gracias a una bien calibrada variación en grosor e inclinación, produce un efecto de matizada ondulación que refuerza el modelado (figs. 3, 6, 7, 8 y 9) en estas zonas - evitándose así el tipo, algo más monótono, de mallas de rombos (o plazas) de la primera cartela, tan cercana aún a Herrera «el Viejo». En la fig. 5 se aprecia cómo numerosas tallas delicadas, en las que se juega deliberadamente con el adelgazamiento del surco a medida que se disminuye progresivamente la presión ejercida sobre el buril, complementan las redes de plazas, siendo éste un recurso que se maneja con maestría en otras tantas cartelas (figs. 4, 7, 9 y 10). Estas sutilezas se combinan con una animada gama de líneas abiertas a buril, tenues y ligeramente curvas, tanto cortas como medianas, que permiten esbozar superficies y contornos sin cargar las tintas. Destaca por su virtuosismo en el aprovechamiento de las múltiples posibilidades que ofrece el grabado calcográfico la octava cartela (fig. 8). Los roleos que enmarcan la escorzada cara grotesca que corona esta orla evidencian el carácter exploratorio que anima a esta serie de composiciones. La superficie de la espiral derecha viene definida por tenues trazos paralelos, de curvatura apenas perceptible. Herrera, en vez de utilizar una línea de contorno para definir el borde inferior de la espiral, recurre a un aumento súbito de la presión, sirviéndose únicamente de la brusca variación de grosor dentro de un surco continuo para definir el cambio de superficie (fig. 13). Se trata, además, de una técnica que se utiliza con igual maestría en los demás roleos de la zona derecha de la cartela. En esta, aunque tímida y focalizada, utilización del lenguaje de la taille simple, Herrera «el Mozo» parece aventurarse

\footnotetext{
${ }^{37}$ Alfonso E. Pérez Sánchez, Mostra di disegni spagnoli, Florencia 1972, pp. 68-69 cat. nos. 66 y 67; Pérez Sánchez y Navarrete Prieto 1995 , p. 113 , cat. no. 33; ibid. 1996, pp. 366-368.

${ }^{38}$ Para ejemplos de remates jónicos en máscaras y cabezas, cfr. Evangelina Borea y Ginevra Mariani, Annibale Carracci e i suoi incisori, Roma 1986, pp. 181-189.

${ }^{39}$ Renato Bruscaglia, Incisione calcografica e stampa originale d'arte: materiali, procedimení, segni grafici, Urbino 1988, p. 21, los describe como «tratteggi 'modellanti'» que, por su complejidad, requieren una gran precisión, no pudiendo conseguirse sin un notable esfuerzo mental. A los Carracci en concreto vendría asociada una consciente utilización de las variaciones de frecuencia del «segno».
}

$A E A$, LXXVIII, 2005, 311, pp. 245 a 261 

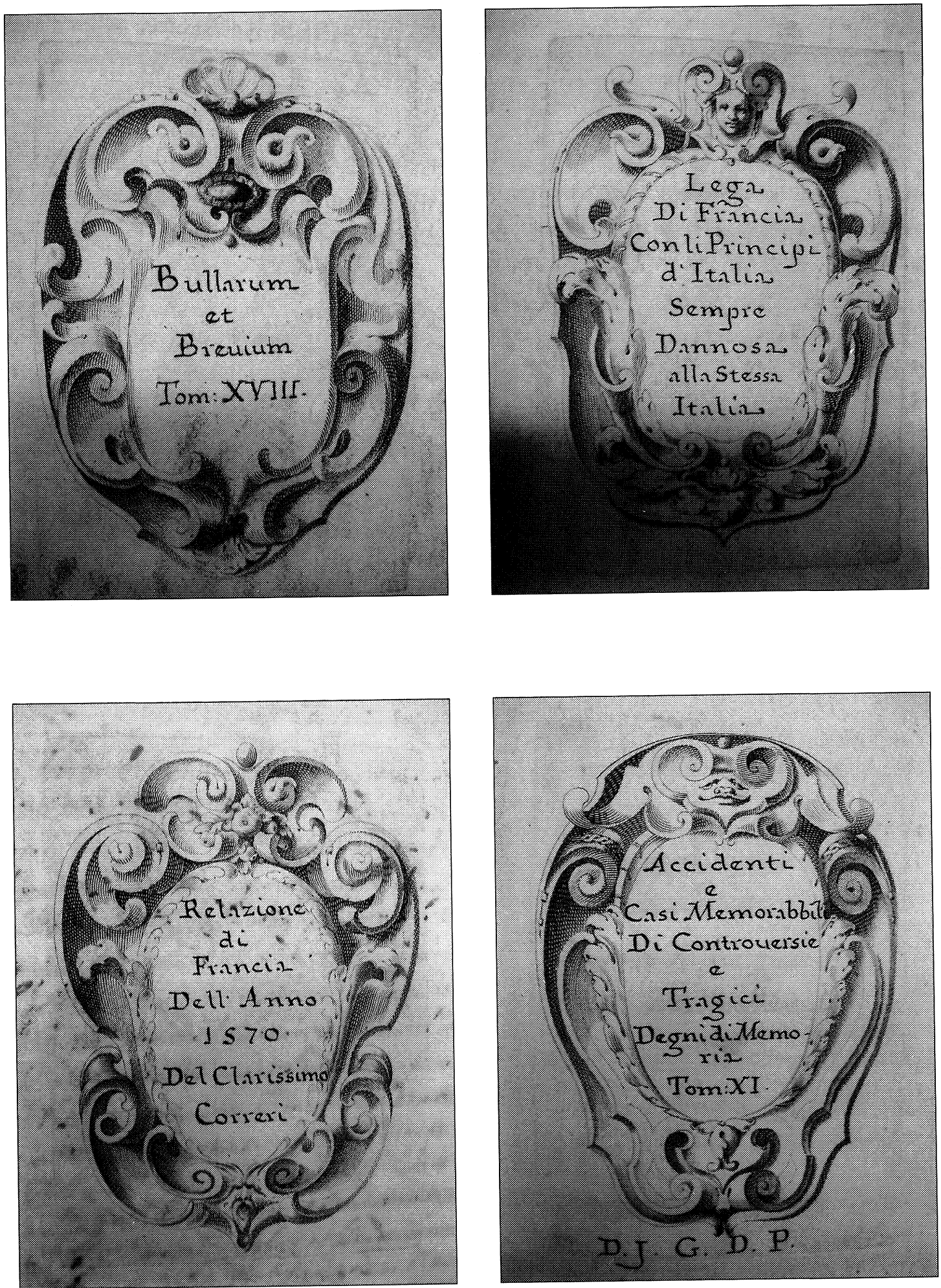

Fig. 5. Grabado de Francisco de Herrera y caligrafía de José García del Pino. Frontispicio del códice 224 (BAEESS, Roma) Fig. 6. Grabado de Francisco de Herrera y caligrafía de José García del Pino. Frontispicio del códice 256 (BAEESS, Roma). Fig. 7. Grado de Francisco de Herrera y caligrafía de José García del Pino. Frontispicio del códice 257 (BAEESS, Roma). Fig. 8. Grabado de Francisco de Herrera y caligrafía de José García del Pino. Frontispicio del códice 309 (BAEESS, Roma). 
más allá de la ortodoxia de la talla ordenada (taille rangée), rasgo vanguardista difícil de imaginar en la Sevilla de su época ${ }^{40}$. Tomada en su conjunto, la serie herreriana, a pesar de sus imperfecciones, pone de manifiesto un alto grado de sofisticación y curiosidad en el manejo del buril, que se corrobora con una búsqueda paralela, a partir de una bien digerida impronta carraccesca, de nuevos recursos formales.

Una serie de cartelas grabadas tan amplia y homogénea como la de Francisco de Herrera «el Mozo» no resulta de fácil parangón ni siquiera en Italia, país por excelencia de este género artístico ${ }^{41}$. De hecho, la serie de trece del boloñés Domenico Santi il Mengazzino (1621-1694) mereció figurar en el Thieme-Becker como obra notoria en el campo del grabado de un por lo demás no muy destacado artista ${ }^{42}$. Sabemos, además, que este género ornamental se cultivó con particular éxito en ambiente romano-boloñés. La figura de Agostino Carracci descuella por calidad e inventiva, siendo sus varios escudos cardenalicios verdaderas obras maestras de un género que encontró eco en los varios y excelentes grabadores que trabajaron bajo su influjo y que, en algunos casos, han llegado a confundirse con el propio maestro ${ }^{43}$. Destacan, entre otros, Francesco Brizio (Bolonia 1575-1623), Oliverio Gatti (Piacenza-Bolonia, activo 16021628), Giovanni Battista Coriolano (Bolonia 1590-1649), Ludovico Ciamberlano (Urbino 1586-Roma 1641) y Giovanni Luigi Valesio (Correggio 1583? - Roma 1633) —este último, de supuesto origen hispano, abrió una de las láminas reutilizadas más tarde, como apuntamos, por García del Pino.

Aunque se ha argumentado que la huella de los grabados de los Carracci es patente en la obra de Herrera «el Viejo» ${ }^{44}$, no parece sin embargo que se pueda argumentar que éste tuviera acceso a una amplia gama de estampas carraccescas. En efecto, un exhaustivo rastreo de fuentes grabadas en la pintura barroca andaluza ha contribuido a desmontar tópicos, aclarando que la circulación de estampas de los Carracci, a tenor de su débil reflejo en la pintura, debió ser escasa y, en cualquier caso, muy inferior al contingente más que considerable de estampas nórdicas, preferentemente flamencas, que se adaptaban perfectamente a la ingente demanda devocional ${ }^{45}$. Aparentemente, la obra que el franciscano Francesco Gonzaga dedicó a la historia de su orden, sobrepasando el centenar de estampas, debió representar el aporte más sustancial de grabados de Agostino Carracci o de factura próxima a éste en la Sevilla de la primera mitad del siglo XvII ${ }^{46}$. No queremos por ello decir que Herrera «el Viejo» no tuviese acceso a otros grabados de los

\footnotetext{
${ }^{40}$ Compárese con el virtuosismo técnico y la búsqueda consciente de nuevos recursos formales típica de la estampa romana de la primera mitad del Seicento: Luigi Ficacci, Claude Mellan, gli anni romani: un incisore tra Vouet e Bernini, Roma 1989.

${ }^{41}$ Género éste de las cartelas y orlas grabadas cultivado con particular éxito en la Italia siglo XVI; véase Elizabeth Miller, $16^{\text {th }}$-Century Italian Ornament Prints in the Victoria and Albert Museum, Londres 1999, pp. 43-51.

${ }^{42}$ The Illustrated Bartsch, vol. 42 (olim 19), pp. 198-210. Ulrich Thieme y Felix Becker, Allgemeines Lexikon der bildenden Künstler, Leipzig 1907-1950, vol. 29 (1935), p. 431, recoge sólo doce «Familienwappen» cuando, en realidad, la serie de cartelas, que no de escudos, incluye trece. De la dependencia de Santi hacia modelos carraccescos, tan evidente, da buena muestra el que nos dejase retratos grabados de Ludovico, Annibale y Agostino (The Illustrated Bartsch, vol. 41 (olim 19), pp. 212-214). Son asimismo célebres las series de Stefano Della Bella.

${ }^{43}$ The Illustrated Bartsch, vol. 39 (olim 18/1), pp. 198-221. Para cambios de atribución de Agostino Carracci a Francesco Brizio, véase: ibid., vol. 40/1 (olim 18/2), p. 188 ss.

${ }^{44}$ Véase Laguna Paúl 1995, pp. 135 y 143, con referencia a Martínez Ripoll.

${ }^{45}$ Benito Navarrete Prieto, La pintura andaluza del siglo xvII y sus fuentes grabadas, Madrid 1998, p. 301: «Las estampas de los Carracci, aunque citadas por Pacheco como ejemplos a imitar, no parece que fuesen tan conocidas y divulgadas, a juzgar por lo que hemos podido ver a lo largo de nuestra investigación».

${ }^{46}$ Cfr. Juana Hidalgo Ogáyar, «Diego Gómez, pintor-iluminador del siglo xviı», en Velázquez y el arte de su tiempo, Madrid 1991, pp. 239-246 (p. 243, fig. 4) donde se reproduce un escudo familiar con cariátides de Diego Gómez, pintor e iluminador en contacto con Pacheco, que recuerda a grabados carraccescos de la obra que dedicara Francesco Gonzaga a los orígenes de la orden franciscana. Como especifica Laguna Paúl 1995, p. 143, Martínez Ripoll ya apuntó la posibilidad de que las sevillanas yeserías del convento de San Buenaventura estuvieran inspiradas en la obra de Fray Francesco Gonzaga ya que este libro se encontraba en la biblioteca del Convento de San Francisco de Sevilla. Véase Francesco Gonzaga, De origine Seraphicae Religionis Franciscanae, Roma 1587 [ejemplar procedente del Convento de San Gil conservado en
} 

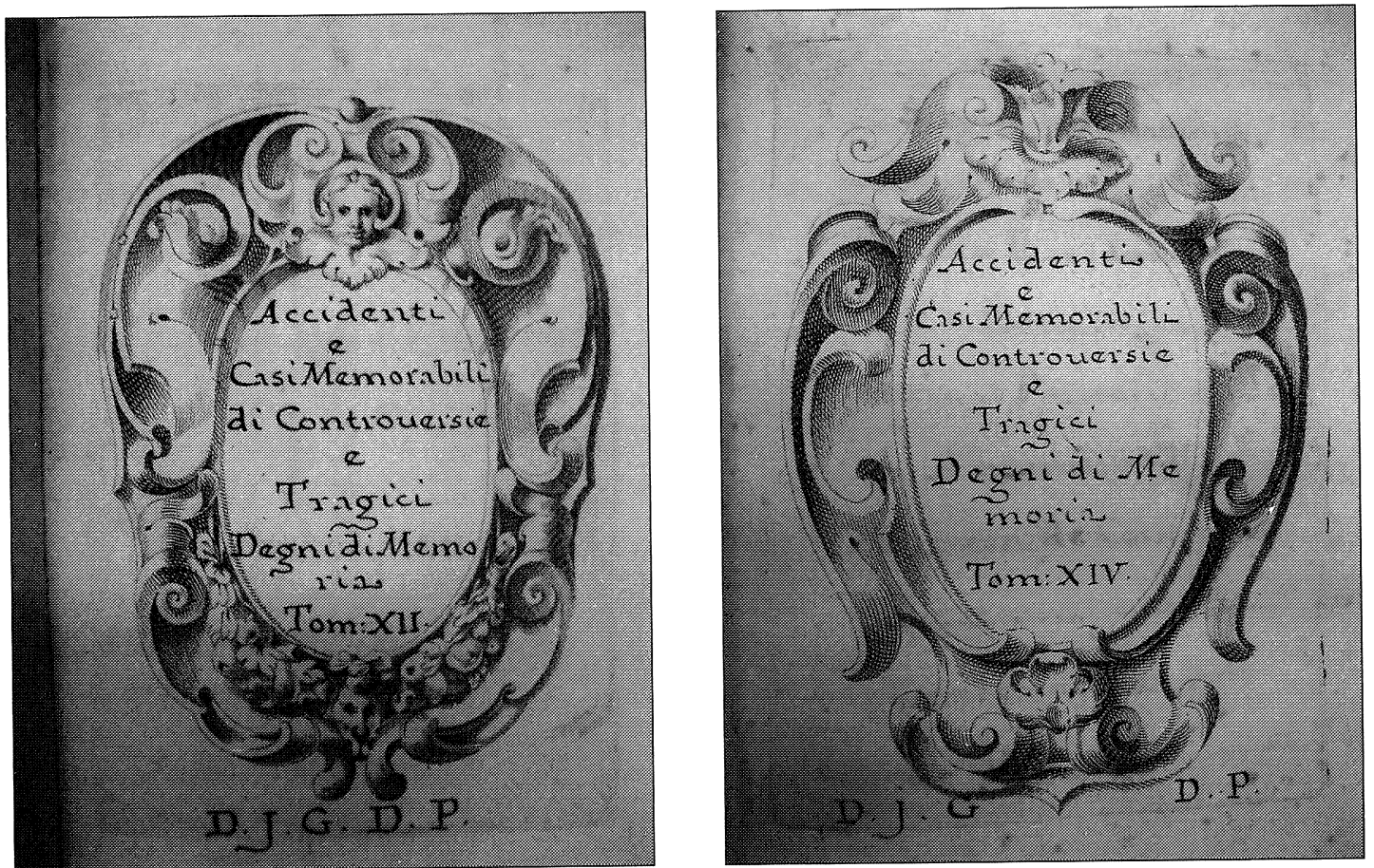

Fig. 9. Grabado de Francisco de Herrera y caligrafía de José García del Pino. Frontispicio del códice 310 (BAEESS, Roma). Fig. 10. Grabado de Francisco de Herrera y caligrafía de José García del Pino. Frontispicio del códice 312 (BAEESS, Roma).

Carracci, pero sí enfatizar que, dada su obra grabada hasta 1627 inclusive ${ }^{47}$, poco hacía presagiar Ia familiaridad con los recursos formales del mejor Agostino Carracci y de su escuela, que se hace evidente en la serie de cartelas de los códices de la Embajada, llevada a cabo más de dos décadas después y que aquí atribuimos sin dudas a su hijo Francisco «el Mozo» ${ }^{48}$. Es más, estas

la RAH 3/8162], especialmente: frontispicio, pp. 264, 324, 340, 366, 376, 384, 438, 452, 463, 510, 580, 660, 685, 844, 1320 y 1346 (los tres últimos, de altísima calidad, son obviamente atribuibles al propio Agostino Carracci).

${ }^{47}$ Por ejemplo, la cartela central con el retrato de San Ignacio de Loyola en la obra de Francisco de Luque Fajardo Relacion de la fiesta que se hizo en Sevilla a la Beatificacion del Glorioso S. Ignacio fundador de la Compañia de Iesus, (Sevilla 1610) es retomada con pocas variantes en la cartela central del Patronato de la Orden Trinitaria (1627). Los frontispicios de los Commentarii in Summam Theologiae S. Thomae (Sevilla 1623), obra de J. Granado, y de las Constituciones del Arçobispado de Seuilla (Sevilla 1609) adolecen de una enfática frontalidad y son, en sí mismas, prueba de la limitada gama de estampas carraccescas a disposición de Herrera «el Viejo».

${ }^{48}$ Abundando más, una sintonía tan afinada con el grabado romano y boloñés en alguien de las características de Herrera «el Viejo» se nos antoja muy improbable. No se olvide que el repertorio de cartelas tardomanieristas en relieves, retablos e interiores arquitectónicos se mantiene prácticamente inalterado en Sevilla durante la primera mitad del siglo xvII (Laguna Paúl 1995, p. 143). Tras la posible pérdida de su mujer y el divorcio y posterior fuga de su hijo, no parece tampoco que la dramática circunstancia de una Sevilla asediada por la peste se prestase a la creación por parte de un artífice solo y entrado en años de una serie de cartelas que, como género, carece de precedentes en el grabado español (Martínez Ripoll 1978 , pp. 37 y 42 es de opinión contraria, aun cuando reconoce que la población sevillana quedó prácticamente diezmada y da como muy posible el fallecimiento por esas fechas de María de Hinestrosa, esposa del pintor, aparte del desagradable abandono familiar de su hijo Francisco «el Mozo», divorciado en circunstancias aun no esclarecidas de Juana de Medina y Auriolis). Para las carencias del grabado ornamental en la España del xvII, véase Juan Carrête Parrondo «El grabado y la estampa barroca», en Juan Carrete Parrondo, Fernando Checa Cremades y Valeriano Bozal, El grabado en España (siglos xv al XVIII), Madrid 1987, pp. 201-391; Juan Carrete Parrondo, «La estampa como adorno» y «La estampa documento», en Estampas: cinco siglos de imagen impresa, Madrid 1981, pp. 173-196 y pp. 201-207. Lo más cercano a la serie de Herrera «el Mozo» son algunas orlas de emblemas, aunque éstas suelen ser de formato apaisado y de dimensiones más modestas, por no mencionar una ejecución convencional y estilísticamente atrasada. El escaso relumbrón de este tipo de estampas ornamentales tampoco casa con un artífice como Herrera «el Viejo», con una situación económica desahogada (Martínez Ripoll 1978, p. 42 (nota 180)), ni se entiende bien en el contexto de crisis generalizada del grabado español en la segunda mitad del siglo xvII (Moreno Garrido y Gamonal 1984, p. 34).

AEA, LXXVIII, 2005, 311, pp. 245 a 261 
cartelas tienen una mayor similitud, en la simplificación de algunos recursos, con grabados de la generación posterior a los Carracci, ya bien entrado el siglo xvII. La máscara en la zona inferior de la segunda cartela se asemeja a la que aparece en cualquiera de los cinco estados o variantes de las armas del Cardenal Peretti, grabados por Agostino Carracci y sus seguidores ${ }^{49}$. La cara en la base de otra cartela, la cuarta, tiene unos rasgos muy próximos a la que aparece en un grabado de Giovanni Battista Coriolano, un pupilo del ya mencionado Valesio ${ }^{50}$. Otro alumno de Valesio, Giacomo Lodi, puede haber servido a su vez de inspiración para la cara grotesca de fauces abiertas de la séptima cartela de Herrera ${ }^{51}$.

El influjo de Agostino Carracci y su escuela en esta decena de grabados de Herrera «el Mozo» quizás sirva para incidir sobre otros aspectos de la singularidad del pintor sevillano en la España de su época. El carácter tardomanierista de las figuras, recurrente en la pintura y en los dibujos de Herrera ${ }^{52}$, recuerda a la interpretación grabada que hace Agostino de la pintura veneciana - y en particular de Veronese. Parte de la idiosincrasia de Herrera «el Mozo» en la España del xvir se debería cifrar en su compleja asimilación del influjo italiano, que - contrariamente a lo sugerido por Kinkead - quizás vaya más allá de la genérica amalgama de venecianismo y ecos rubensianos con la que se da cuenta, a veces de forma ya casi tópica, de la formación de los artistas cortesanos en el Madrid de Felipe IV y de Carlos II. El quizás más sobresaliente cuadro de Herrera que nos ha llegado, dentro de una producción fatalmente mermada, sea el Triunfo de San Hermenegildo (1654) del Prado (fig. 11). En él Herrera, más que servirse de fórmulas ya definidas, da muestras de una inventiva notable y de una poco frecuente amplitud de criterio. Ya desde Palomino se ha señalado el marcado contraste lumínico como uno de los distintivos de Herrera, dejando una estela de admiración en pintores como Matías de Torres ${ }^{53}$ o Martínez Cabezalero ${ }^{54}$. Esta utilización efectista del contraluz ${ }^{55}$ no se distancia del uso cerebral del contraste lumínico que se evidencia en las cartelas aquí estudiadas y tampoco queda lejos de ejemplos significativos de la pintura veneciana del quinientos y seiscientos. Los esbeltos ángeles músicos y el populoso coro celestial en el rompimiento de gloria de los Desposorios místicos de Santa Catalina, grabado por Agostino Carracci en base al lienzo de Veronese, hoy en la Galleria dell'Accademia (Venecia), ponen de manifiesto el particular sesgo que éste sobrepone a una pintura que indudablemente conocía de primera mano. Algo similar se podría objetar en la interpretación nada servil que Herrera hace de sus modelos italianos. El gusto de Herrera por los ángeles músicos de bien definida musculatura coincide con el de Agostino Carracci ${ }^{56}$, del mismo modo que la cuidada anatomía de sus «academias» indica, como ya se ha señalado, familiaridad con el medio académico romano ${ }^{57}$. Curiosamente, la

\footnotetext{
${ }^{49}$ The Illustrated Bartsch, vol. 39/1: Comm. (olim 18/1), pp. 346-349 (esp. la variante .211S5) y vol. 39 (olim 18/1), p. 216.

50 The Illustrated Bartsch, vol. 41: Comm. (olim 19/1), p. 172.

${ }^{51} \mathrm{Ibid}$., p. 352. Este tipo de caras son de ascendiente carraccesco y no son infrecuentes entre los seguidores de Agostino Carracci.

${ }^{52}$ Pérez Sánchez y Navarrete Prieto 1995, pp. 152-153, cat. no. 59, notan respecto a la «Apoteosis de la Ciudad de Sevilla» (BNM Barcia 380) que las figuras alegóricas «evocan modelos manieristas».

${ }^{53}$ Palomino de Castro 1986, p. 381.

${ }^{54}$ Alfonso E. Pérez Sánchez, «Precisiones sobre Juan Martínez Cabezalero», en Velázquez y el arte de su tiempo, Madrid 1991, pp. 247-257 (pp. 254-255).

${ }^{55}$ Que, en el caso de su «Jesús nazareno caído con la Cruz a cuestas», Palomino localiza en «casa de un aficionado» y describe como digno de compararse con Tiziano por «superiormente conducido, y observado de luz» (Palomino de Castro 1986, p. 282). El uso caprichoso de luces y sombras fue, en Herrera, «singularísimo» (ibid., p. 281).

${ }^{56}$ Bury 2001, p. 75, cita el comentario de Charles Dempsey al respecto de la mayor definición anatómica que Agostino Carracci confiere a las figuras veronesianas. Diego Angulo Íñiguez, Pintura del siglo XVII, Madrid 1958, p. 285, nota los «desnudos nacarinos» de Herrera «el Mozo».

${ }^{57}$ En concreto Pérez Sánchez 1972, p. 17, estima que Herrera «el Mozo» conocía la gráfica cortonesca. Véase asimismo Pérez Sanchez y Navarrete Prieto 1995, pp. 174-177, cat. nos. 70-71 y Reyes Durán González-Meneses, Catálogo de los dibujos de los siglos XVI y xvil de la Colección del Museo de la Casa de la Moneda, Madrid 1980, cat. nos. 30-35.
}

$A E A$, LXXVIII, 2005, 311, pp. 245 a 261 

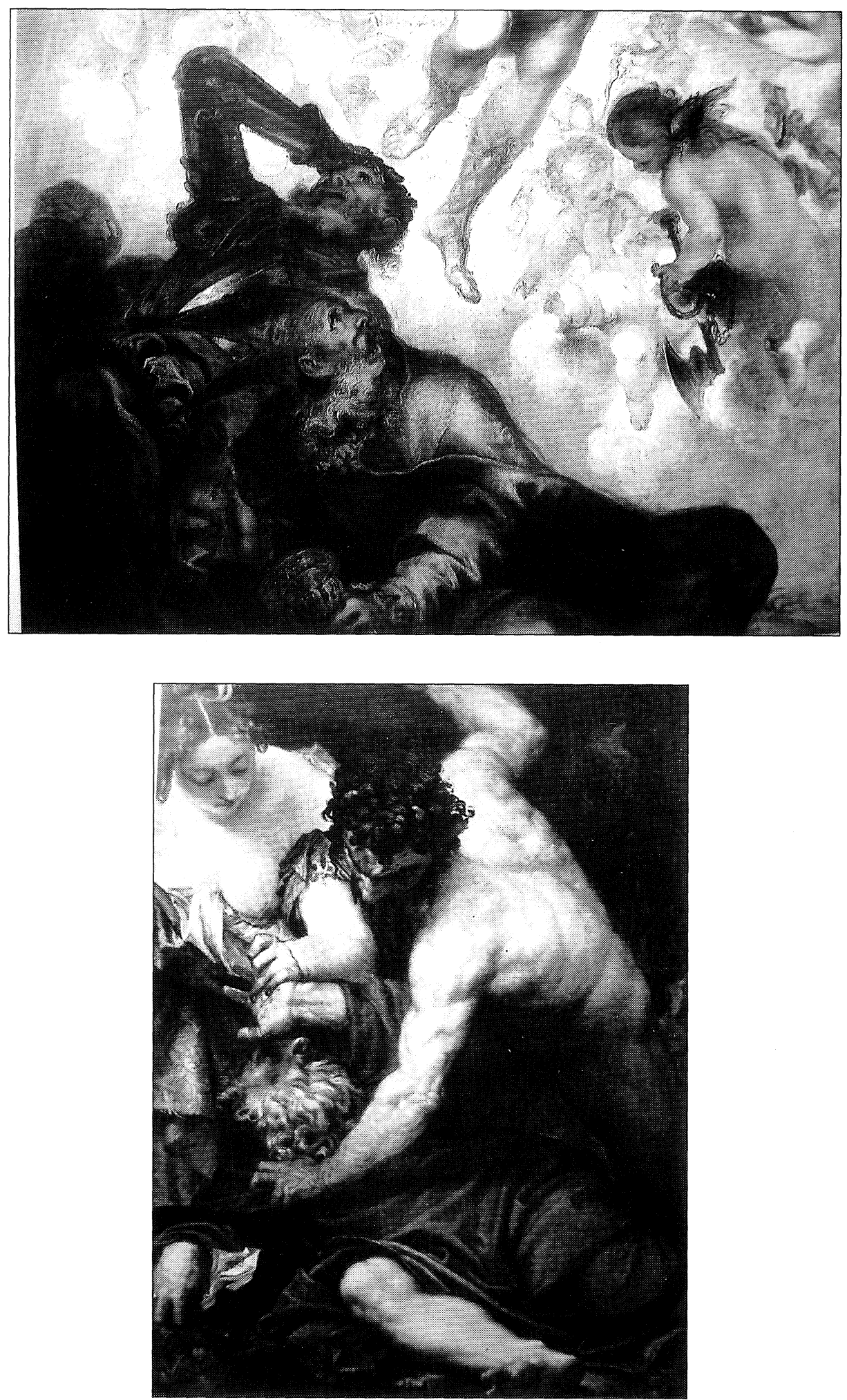

Fig. 11. Francisco de Herrera. Detalle del Triunfo de San Hermenegildo (Museo del Prado, Madrid). Fig. 12. Paolo Veronese. Detalle de San Antonio tentado por el diablo (Musée des Beaux-Arts, Caen). 
labor de puente entre el mundo véneto y el primer clasicismo romano-boloñés del XVII ${ }^{58}$, que pertenece por derecho propio a Agostino Carracci ${ }^{59}$, encuentra un eco en Herrera «el Mozo», capaz de aunar ecos del colorido de Veronese, del brío compositivo y de la segura ejecución de Tintoretto con fórmulas gráficas de raigambre romano-boloñesa. Lo poco previsible que tiene el estilo pictórico de Herrera apunta - y la crítica así lo recoge - a un aprendizaje romano como hecho diferencial, complementado con influencia veneciana ${ }^{60}$. No por tratarse de un género menor, las cartelas grabadas dejan de corroborar una experiencia directa de la Roma pamphiliana con posibles estancias en Venecia y Bolonia.

La destrucción de ejemplos de pintura al fresco atribuibles a Herrera ${ }^{61}$ y lo escasísimo que conocemos de su actividad como arquitecto limitan considerablemente nuestra capacidad para comprender adecuadamente la entidad de este «excelentissimo» pintor-arquitecto ${ }^{62}$ y su impacto en el barroco español. Sin embargo, la calibrada relectura que hiciera Beatriz Blasco de su malogrado proyecto para El Pilar de Zaragoza pone de manifiesto lo innovador de la planta respecto de la solución tradicional propuesta por Felipe Sánchez ${ }^{63}$. Tanto Jiménez Donoso como Teodoro Ardemans se situarían próximos a Herrera, que también mereció el elogio de Palomino ${ }^{64}$ y que se configura como un personaje decisivo en la superación de modelos arcaizantes en beneficio de soluciones más novedosas. Ya se ha hecho hincapié en el papel de Herrera como difusor en Sevilla y Madrid de las academias artísticas al uso romano ${ }^{65}$, papel que se podría quizás especificar más con su probable adhesión a fórmulas carraccescas en ornato y neovenecianas en pintura. Resulta por otro lado frustrante que la pérdida de aspectos fundamentales de la producción de Herrera «el Mozo» impida profundizar adecuadamente en su evolución estilística o en su capacidad efectiva de influenciar el entorno cortesano. Llama la atención que sus «borrones» se conservasen o coleccionasen, dato que apunta a una apreciación muy significativa de su arte ${ }^{66}$.

Dentro del ascendiente predominantemente ticianesco del venecianismo hispano del siglo XVII ${ }^{67}$, Herrera «el Mozo» quizás ocupe un lugar de excepción por su adhesión a Veronese,

\footnotetext{
${ }^{58}$ Como bien dice Walter Vitzthum, Il Barocco a Roma, Milán 1970, p. 7, «la linea di demarcazione fra le scuole di Bologna e di Roma rimane mal definita per i primi tre decenni del Seicento».

${ }^{59} \mathrm{El}$ uso por parte de Annibale de dibujos y estampas de Agostino es constante, siendo además el hermano mayor, tras sus dos viajes a Venecia en 1582 y 1589 , el propagador por antonomasia de la pintura véneta en medio boloñés primero y romano después. Diane De Grazia, Le stampe dei Carracci con i disegni, le incisioni, le copie e $i$ dipinti connessi, ed. A. Boschetto, Bologna 1984, p. 129. El viaje (o viajes) de Annibale a Venecia se da como muy probable por la crítica especializada.

${ }^{60}$ Angulo Íñiguez 1958, pp. 280-285, le atribuye «un sentido cromático, y un estudio de la luz probablemente aprendido en la Venecia de su tiempo».

${ }^{61}$ Perdidas para siempre sus obras al fresco para Atocha, los Agustinos Recoletos o San Felipe El Real.

${ }^{62}$ Ardemans lo define «excelentissimo pintor arquitecto universal» en su «Mantisa de los mas Insignes Arquitectos, que han professado à vn tiempo la Pintura, y Arquitectura» (véase Teodoro Ardemans, Declaracion y extension sobre las ordenanzas, que escriviò Juan de Torija, Madrid 1719, pp. 275-287 (p. 282)).

${ }^{63}$ Beatriz Blasco Esquivias, «En defensa del arquitecto Francisco de Herrera el Mozo. La revisión de su proyecto para la basílica del Pilar de Zaragoza, en 1695», Cuadernos de arte e iconografía, 3.6 (1990), pp. 65-76. Virginia Tovar Martín es mucho más reticente en cuanto a la originalidad del proyecto de Herrera (Arquitectos madrileños de la segunda mitad del siglo xvII, Madrid 1975, pp. 352-354) y, en general, atribuye un papel del todo secundario como tracistas a Herrera y Jiménez Donoso, pintores arquitectos de formación italiana (ibid., p. 239).

${ }^{64}$ Nos dice que Herrera volvió de Roma «no sólo gran pintor, sino consumado arquitecto, y perspectivo» (Palomino de Castro 1986, p. 281).

${ }^{65}$ Brown 1974, pp. 130-132; Pérez Sánchez 1986, p. 94; Pérez Sánchez y Navarrete Prieto 1995, pp. $176-177$.

${ }^{66}$ Don Gaspar de Haro, VII Marqués del Carpio, conservaba una «Gloria con muchos santtos que es el borroncillo que está pintado en el coro de san Felipe», obra de Herrera (Marcus B. Burke y Peter Cherry, Collections of Paintings in Madrid, 1601-1755, Los Ángeles 1997, vol. 2, inv. 115, no. 414). Este mismo borrón debió ser el utilizado más tarde para la restauración que siguió al incendio de 1718, ya que dice Palomino que se retocó entonces «aunque por [el] propio borroncillo [de Herrera]» (Palomino de Castro 1986, p. 281).

${ }^{67}$ Alfonso E. Pérez Sánchez, «Veronese e la Spagna nel Seicento», Nuovi studi su Paolo Veronese, ed. M. Gemin, Venecia 1988, pp. 94-107.
}

$A E A, \mathrm{LXXVIII,} 2005,311$, pp. 245 a 261 
como se trasluce de su Apoteosis de San Hermenegildo. El angelillo que sostiene una palma a la derecha del santo rey recuerda poderosamente por disposición y anatomía a uno de los puttini sobrevolando los Desposorios místicos de Santa Catalina de Veronese, ya sea en el original conservado en la Galleria dell'Accademia como en la versión grabada por Agostino Carracci ${ }^{68}$. El propio rey godo, en su manera airosa de flotar, su elegante anatomía y vigoroso impulso ascendente, recuerda modelos veronesianos ${ }^{69}$. Un ágil apunte de Herrera para una resurrección (BNM Barcia 377) ha sido acertadamente puesto en relación con el San Hermenegildo ${ }^{70}$; da este dibujo además prueba de la asimilación profunda en Herrera de la pintura veneciana ${ }^{71}$ y de su familiaridad con el grabado italiano de la primera mitad del siglo xvII, dada su marcada semejanza con un modelo de Raffaello Sciaminossi ${ }^{72}$. También responde a precedentes vénetos el contraste acentuado de luz entre las figuras en sombra del primer plano y la figura de San Hermenegildo - contraste que se dobla con la tensión diagonal entre estas últimas y la figura principal, un recurso también frecuente en la obra de Veronese ${ }^{73}$ y de Tintoretto ${ }^{74}$. Resulta por último sorprendente el parecido entre el prelado despavorido a los pies de San Hermenegildo y el santo ermitaño asediado del San Antonio tentado por el diablo de Veronese (Musée des Beaux-Arts de Caen, fig. 12), que Herrera bien pudo conocer en Génova ${ }^{75}$, en su camino de ida o de vuelta a Roma. Cabría añadir, dentro de la influencia veneciana, que los dos grandes lienzos de Herrera «el Mozo» ${ }^{76}$, procedentes de la Capilla de Nuestra Señora de los Siete Dolores del Colegio de Santo Tomás, hoy conservados en el Museo Cerralbo, tienen una notable afinidad con Tintoretto; lo que Palomino describe como «acabar» $\mathrm{y}$ «golpear a su modo en toda forma», sobre una pintura iniciada por Francisco Ignacio Ruiz de la Iglesia a partir de «borroncillos» del propio Herrera ${ }^{77}$, concuerda además con la pincelada enérgica y sintética observable en las figuras en contraluz a los pies del San Hermenegildo del Prado, de claros ecos venecianos. El modo de esbozar el fondo en los cuadros del Cerralbo, con pocas y precisas pinceladas sobre un fondo oscuro, evoca la maniera tarda de Tiziano y el quehacer de Tintoretto, especialmente en la Scuola Grande di San Rocco (Venecia).

En efecto, si la atención de Agostino Carracci por la pintura veneciana se focaliza en Veronese y Tintoretto, resulta convincente pensar que un Herrera «el Mozo» vinculado a prestigiosos (aunque escasos) modelos de Agostino Carracci ya desde el taller paterno, buscase una vez en Italia fuente de inspiración en estos maestros. La serie de cartelas de estilo Carracci

\footnotetext{
${ }^{68}$ Se trata del angelillo que se sitúa inmediatamente sobre el Jesús niño, sosteniendo una corona (para cotejar el grabado de Carracci y el original de Veronese, véase De Grazia 1984, figs. 131 y 131a).

${ }^{69} \mathrm{La}$ manera de adelantar una pierna y de levantar un brazo a la vez, la palma abierta de la otra mano, con la característica separación de los dedos a excepción del anular y corazón, la cara vuelta y la utilización de la luz para intensificar el movimiento de la figura, todo ello recuerda al «Giove che scaccia i Vizi» de Veronese (Museo del Louvre). Ciertamente, la elegante figura de San Hermenegildo se puede asociar a los resucitados de Veronese, ya sea el de San Francesco della Vigna (Venecia) o el de Westminster (Londres).

${ }^{70}$ Elena Santiago Páez, en Del amor y la muerte: dibujos y grabados de la Biblioteca Nacional, Madrid 2001, p. 37 y pp. 278-279, cat. no. 99 .

${ }^{71}$ Piénsese, entre otras, en la ya mencionada Resurreción de Veronese en San Francesco della Vigna, en la de Tiziano en Santi Nazario e Celsio (Brescia) o la de Tintoretto en la Scuola Grande di San Rocco.

${ }^{72}$ The Illustrated Bartsch, vol. 38 (olim 17/5), p. 91 (reproducida también por Ludovico Ciamberlano, vol. 44 (olim 20/1)).

${ }^{73}$ Por ejemplo, la Transfiguración del Duomo de Montagnana.

${ }^{74}$ Un buen ejemplo sería la Tentación de San Antonio (S. Trovaso, Venecia). Algunas obras de Tintoretto eran accesibles, además, por vía de estampas; véase Maria Agnese Chiari Moretti Weil, Jacopo Tintoretto e i suoi incisori, Milán 1994, passim.

${ }^{75}$ Del aprecio que merecía esta obra da la medida el que fuera dibujada por Fragonard en pleno siglo xvIII (Pierre Rosenberg, «Veronese et les voyageurs français du XvIII ${ }^{\mathrm{e}}$ siècle», in Nuovi studi su Paolo Veronese, ed. M. Gemin, Venecia 1990, pp. 121-128 (p. 126)).

${ }^{76}$ Se trata de un Ecce Homo y de un Camino del Calvario. Véase Palomino de Castro 1986, p. 282.

${ }^{77}$ Palomino de Castro 1986, p. 282.
} 
desarrolladas en Roma encajaría perfectamente con estos parámetros, dándose además la circunstancia que la potenciación de la asimetría compositiva (subyacente al San Hermenegildo de Herrera) es algo que los Carracci adoptaron conscientemente de Venecia ${ }^{78}$. En concreto, y como apoyo de la tesis de un origen romano de la serie de Herrera, la década de 1640-50 en Roma se caracteriza por la emergencia de las tesis clasicistas, hasta entonces cultivadas en círculos eruditos y anticuarios bastante restringidos. Pieza fundamental de ese emerger del clasicismo, para el que Giovan Pietro Bellori resultaría figura fundamental, era la revalorización pública y plenamente asumida de la herencia carraccesca ${ }^{79}$. La serie de Herrera, que por su homogeneidad podemos fechar con seguridad en torno a $1649^{80}$, dada su afinidad con las maneras de Agostino Carracci y su escuela, encaja sin dificultad en un contexto romano clasicista en el que despuntan ya las tendencias que triunfarían plenamente un cuarto de siglo más tarde ${ }^{81}$ y dónde no falta una consciente revalorización de los grandes venecianos del quinientos ${ }^{82}$. No se echa en falta, además, algún eco de pintura boloñesa en la obra pictórica de Herrera, como es el caso del paisaje crepuscular de su Huida a Egipto ${ }^{83}$. En resumen, la singularidad del pintor sevillano no se circunscribe a su receptividad a la pintura veneciana, característica general de la escuela barroca madrileña, sino a su peculiar manera de injertar ecos diversos del arte italiano, que van desde su ágil dibujo, donde se percibe aún la huella del manierismo, hasta una pintura que solapa hábilmente las enseñanzas de Veronese y Tintoretto. Las cartelas ponen de manifiesto, además, que parte del lenguaje decorativo boloñés que introducirían en España Colonna y Mitelli ${ }^{84}$ pudo tener un preludio significativo en Herrera, cuyo vocabulario ornamental parece bien lejos del de Francisco Rizi o Sebastián de Herrera Barnuevo, reconocible por un uso exuberante de querubines y carnosos roleos vegetales. No cabe duda que habría que profundizar más sobre la experiencia romana de Herrera «el Mozo» — cronológicamente paralela a la de su paisano Velázquez- y, quizás, intentar rescatar del olvido algo de su obra arquitectónica y ornamentística, en el supuesto optimista que queden, dispersos y por identificar, restos de su producción gráfica ${ }^{85}$. La personalidad del pintor y arquitecto hispalense, pieza clave de la generación post-velazqueña, podría asociarse a una precoz, aun cuando selectiva, recepción del barroco romano en Madrid ${ }^{86}$. Herrera se situaría en una línea moderadamente ecléctica, a caballo entre lo neoveneciano en pintura ${ }^{87}$ y lo romano-boloñés en obra gráfica, pero claramente unido a pre-

\footnotetext{
${ }^{78}$ Andrea Emiliani et al., Ludovico Carracci, Bolonia [1993], pp. 48-49, cat. no. 22.

${ }^{79}$ Silvia Ginzburg Carignani, «Dialoghi tra Italia e Francia nella giovinezza di Bellori», en L'idéal classique : Les échanges artistiques entre Rome et Paris au temps de Bellori (1640-1700), ed. O. Bonfait, París 2002, pp. 46-68. Sabemos, por ejemplo, que Rubens adquiere en Italia y reutiliza posteriormente dibujos de Annibale Carracci; véase la reseña de Eveliina Paul a la exposición «Rubens: Drawing on Italy», Kunst Chronik, 56.12 (2003), pp. 617-622 (pp. 620-621). Entre 1642 y 1644 un alumno de François Perrier, François Bourlier, copió numerosos dibujos de la colección de dibujos de Annibale Carracci del anticuario Angeloni (Catherine Loisel Legrand, «The Fate of Annibale's Drawings», en The Drawings of Annibale Carracci, Washington / Londres 1999-2000, pp. 24-33 (p. 27)).

${ }^{80} \mathrm{La}$ homogeneidad estilística se refleja además en las medidas de la huella de impresión que apenas varían, situándose su anchura entre 11,1 y $11,5 \mathrm{cms}$ y su altura entre 15 y $16,5 \mathrm{cms}$.

${ }^{81}$ Renato Roli, I Disegni italiani del Seicento, Treviso 1969. p. xv, enfatiza que el predominio del clasicismo en Roma se hace evidente «sin oltre la metà del Seicento».

${ }^{82}$ De ella forman parte Andrea Sacchi, Nicolas Poussin, Pietro Testa y Pier Francesco Mola. Ibid., p. lix-lxi.

${ }^{83}$ Este lienzo en la Ermita del Cubillo (Aldeavieja, Ávila) fue atribuido a Herrera «el Mozo» por Pérez Sánchez 1986, pp. 270-271, cat. n. ${ }^{\circ} 103$.

${ }^{84}$ Véase Salvador Salort Pons, Velázquez en Italia, Madrid 2002, pp. 147-182, y la bibliografía allí citada.

${ }^{85}$ Escribe Palomino que «fue grandísimo arquitecto, y así hizo repetidas trazas para retablos, y obras de arquitectura, que hoy las estiman los artífices cada una, como una joya» (Palomino de Castro 1986, p. 284).

${ }^{86}$ Brown 1975 , pp. $235-236$, sitúa a Herrera «at the very forefront of stylistic change in Spanish Baroque painting».

${ }^{87}$ Pérez Sánchez 1986, p. 267, encuentra similitudes entre Herrera y dos pintores del barroco veneciano, Sebastiano Mazzoni (ca. 1611-1678) y Francesco Maffei (1605-1660), lo que vendría a abundar, especialmentte en lo concerniente al segundo, en el componente veronesiano de Herrera. La luminosidad dorada y los contornos difusos de algunas obras de
} 
supuestos académicos ${ }^{88}$ y a un concepto unificador de las artes bajo la común tutela del «disegno» ${ }^{89}$.

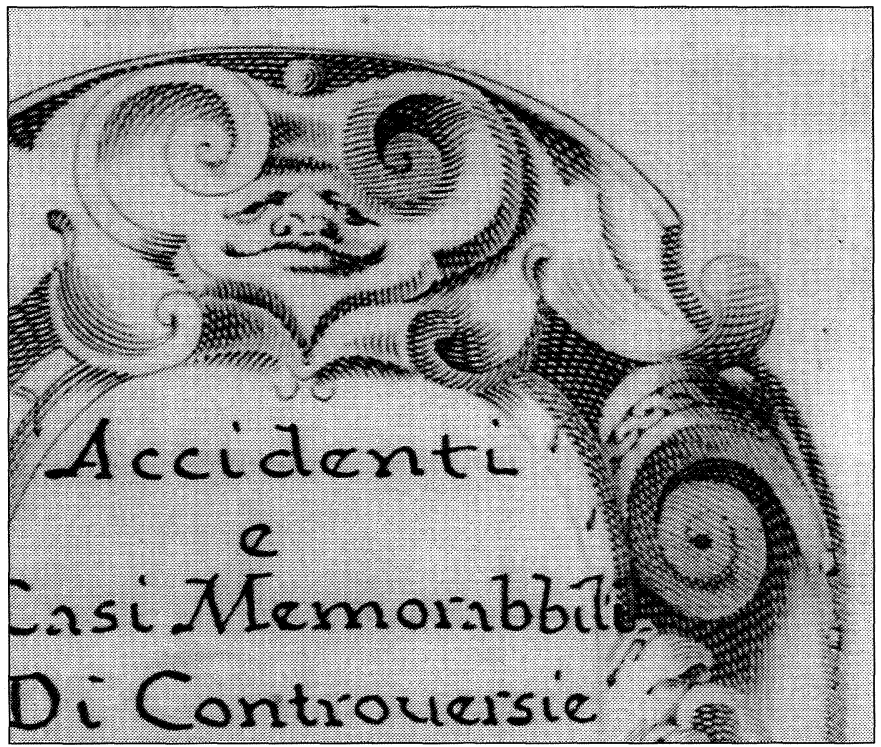

Fig. 13. Detalle de la Fig. 8.

Mazzoni (entre otras, Loth e le Figlie y La Morte di Cleopatra, ambas en la Pinacoteca dell'Accademia dei Concordi, Rovigo) se asemejan, efectivamente, a obras de Herrera «el Mozo», que bien pudo conocer la pintura veneciana de mediados del siglo XVII en la propia Venecia.

${ }^{88} \mathrm{La}$ técnica à deux crayons que utiliza Herrera «el Mozo» en alguno de sus desnudos masculinos ha sido relacionada por Pérez Sánchez y Navarrete Prieto 1995, pp. 174-175, con el círculo de Pietro da Cortona, donde era habitual. De hecho, se puede asociar de manera más genérica con la enseñanza de la Accademia di San Luca, tratándose de una técnica introducida en Roma por Federico Zuccari (Detlef Heikamp, «Zu den Reisezeichnungen Federico Zuccaris», Römische Jahrbuch der Bibliotheca Hertziana, 32 (1997-1998), pp. 347-368 (p. 349)).

${ }^{89}$ Beatriz Blasco Esquivias, «Sobre el debate entre arquitectos profesionales y arquitectos artistas en el barroco madrileño. Las posturas de Herrera, Olmo, Donoso y Ardemans», Espacio, Tiempo y Forma (serie VII: Historia del Arte), 4 (1991), pp. 159-194 (p. 169). Sobre este debate profesional, véase además: ibid., «Il dibattito tra gli 'architetti-puri' e gli 'architetti-artisti' nella Madrid del XVII secolo», Annali del barocco in Sicilia, 5 (1998), pp. 35-47; Fernando Marías Franco, «De pintores-arquitectos: Crescenzi y Velázquez en el Alcázar de Madrid», en Velázquez y el arte de su tiempo, Madrid 1991, pp. 81-89; René Taylor, «Juan Bautista Crescencio y la arquitectura cortesana española (1617-1635)», Academia: Boletín de la Real Academia de Bellas Artes de San Fernando, 38 (1979), pp. 61-126; Alfonso Rodríguez Gutiérrez de Ceballos, sj, «L'architecture baroque espagnole vue à travers le débat entre peintres et architectes», Revue de l'Art, 4.170 (1985), pp. 41-52.

AEA, LXXVIII, 2005, 311, pp. 245 a 261 